\title{
KINETICS OF THE HYDROLYSIS OF CEPHALOSPORIN C
}

\author{
J. Konecny, E. Felber and J. Gruner \\ CIBA-GEIGY Aktiengesellschaft, Basel, Switzerland
}

(Received for publication December 6, 1972)

\begin{abstract}
The decomposion rates of cephalosporin $\mathrm{C}$ in aqueous buffers and in fermentation broth at $25^{\circ} \mathrm{C}$ were determined by high pressure liquid chromatography and were found to obey the rate law $-d C / d t=\left[0.27\left(\mathrm{H}^{+}\right)+0.005+500\right.$ $\left.\left(\mathrm{OH}^{-}\right)\right] C$ mole. $\mathrm{I}^{-1} \cdot \mathrm{h}^{-1}$. In the acidity range from $\mathrm{pH} 3$ to 7 the principal reaction is the slow attack of water on the nucleus. In alkaline and in strongly acidic solutions hydrolysis of the acetyl side chain is sufficiently fast relative to the base or acid catalyzed destruction of the nucleus to produce desacetyl cephalosporin $\mathrm{C}$ or its lactone in appreciable yields. In a typical fermentation non-enzymatic hydrolysis destroys about $15 \%$ of the product.
\end{abstract}

The decomposition of aqueous cephalosporin $\mathrm{C}$ has been discussed in two reviews of the chemistry of cephalosporin $\mathrm{C}$ and its biosynthesis ${ }^{1,2)}$. The original papers, mainly by Newton, ABRAham and coworkers, deal primarily with the nature of the identifiable end products and intermediates formed under acid, neutral and basic conditions of hydrolysis. Except for the work of Huber and coworkers ${ }^{3)}$, who measured the decomposition rate in sterilized and incubated broth at neutral $\mathrm{pH}$, no rate studies of the reaction have been reported.

Since the decomposition rates are of interest in the synthesis of cephalosporin $\mathrm{C}$ derivatives, in the processing of fermentation broth and in fermentation studies, we have investigated the kinetics of the reaction in aqueous buffers representing a wide range of acidity.

The molecule of cephalosporin $\mathrm{G}$ has at least three sites more or less susceptible to attack by hydrogen ions, hydroxide ions and water: the ester group of the acetyl side chain, the amide group of $\alpha$-aminoadipyl side chain and the $\beta$-lactam ring. Due to the complexity of the reaction system, the instability of the intermediates and the associated analytical problems, the present knowledge of the hydrolytic reactions is still incomplete. It is known that the decomposition at neutral $\mathrm{pH}$ is slow and leads to D-4-(2-amino-4-carboxybutyl)-thiazole-4-carboxylic acid as one of the products $^{4}$. Although acids catalyze the removal of the acetyl and the aminoadipic side chains $^{5)}$, cephalosporin $\mathrm{G}$ is still quite stable at room temperature at $\mathrm{pH} 2.5^{6)}$. Acids catalyze the conversion of desacetyl cephalosporin $\mathrm{C}$ to the lactone ${ }^{7)}$ and cleave the nucleus as well'b). Mild acid hydrolysis leads to the formation of the lactones of desacetyl cephalosporin $\mathrm{C}$ and desacetyl-7-aminocephalosporanic acid, and also to 7aminocephalosporanic acid in very low yields ${ }^{5}$. The end products of acid hydrolysis are carbon dioxide and $\alpha$-aminoadipic acid ${ }^{6)}$. Alkaline hydrolysis at pH 9.5 or 11 leads to the formation of desacetyl cephalosporin $C$ as an intermediate together with 
uncharacterized ninhydrin-positive material ${ }^{7)}$. In weak alkali, the $260 \mathrm{~nm}$ UV band, characteristic of the cephalosporin nucleus ${ }^{2)}$, disappears rapidly ${ }^{6,8}$.

In the present work we have followed the decomposition by high pressure liquid chromatography. The method, which is also suitable for the assay of cephalosporin $\mathrm{C}$ in fermentation broths, takes advantage of the $260 \mathrm{~nm}$ UV band of cephalosporin $\mathrm{C}$ and detects the parent compound as well as the intermediates with the intact nucleus. We also report reaction rates as measured by the differential spectrophotometric method of CLARIDGE and coworkers ${ }^{8)}$, which utilizes the large change in optical density at $260 \mathrm{~nm}$, associated with the destruction of the cephalosporin nucleus by weak alkali.

The rate measurements, carried out at $25^{\circ} \mathrm{G}$, span the acidity range from $\mathrm{pH} 1$ to 12.5 and furnish information about the overall reaction and the relative rates of desacetylation and of the destruction of the nucleus in alkaline, neutral and weakly acid solutions. The decomposition rates in neutral aqueous buffers are compared with the decomposition rates in broths and are used to estimate the loss of product in fermentation due to hydrolysis.

\section{Experimental}

All solutions were prepared with analytical grade reagents. The sodium salt of cephalosporin $\mathrm{C} \mathrm{NaC} \mathrm{N}_{16} \mathrm{H}_{20} \mathrm{~N}_{3} \mathrm{O}_{8} \mathrm{~S} \cdot 2 \mathrm{H}_{2} \mathrm{O}$ and the sodium salt of desacetyl cephalosporin $\mathrm{NaC}_{14} \mathrm{H}_{18} \mathrm{~N}_{3} \mathrm{O}_{7} \mathrm{~S}$ were chromatographically pure and their molar extinction coefficients were 8470 and 7900 at $260 \mathrm{~nm}$. The reaction mixtures in which the decomposition was very slow ( $\mathrm{pH} 3 \sim 9$ ) were sterilized by Millipore filtration. The alkaline solutions were kept under nitrogen to exclude atmospheric carbon dioxide. The $\mathrm{pH}$ of the reaction mixtures was measured at $20^{\circ} \mathrm{C}$ with the Metrohm pH meter E 500, using Merck “Titrisol" buffers as standards up to $\mathrm{pH} 12$ and a Metrohm buffer at $\mathrm{pH} 13$.

The runs were carried out in a constant temperature bath maintained at $25.00 \pm 0.05^{\circ} \mathrm{C}$, samples being withdrawn at suitable time intervals. Generally, 2-ml aliquots of the reaction mixture were pipetted into $1 \mathrm{ml}$ of $1 \mathrm{M}$ phosphate buffer $\mathrm{pH} 7$ and were then analysed at once or stored over night at $-20^{\circ} \mathrm{C}$ prior to analysis by liquid chromatography.

The liquid chromatography was carried out under the following conditions.

Apparatus :

Column :

Static phase:

Mobile phase:

Pressure :

Temperature :

Flow rate:

Detector :

Sample size :

Fermentation samples: Aliquots of the samples were generally diluted to approx. $0.01 \%$ active substance (this prolonges column life).

The identity of cephalosporin $\mathrm{C}$ peaks was tested using the sodium hydroxide treatment: aliquots of the sample solutions were held for 30 minutes at $25^{\circ} \mathrm{C}$ the $\mathrm{pH}$ being $12.5 \sim 13$. A complete destruction of all known cephalosporin $\mathrm{C}$ derivatives was observed after this treatment. This method has been applied also for differential analysis, when unresolved peaks of cephalosporins together with ingredients of certain fermentation media appeared.

The test conditions in the differential spectrophotometric assay were as described ${ }^{87}$ 
except for the length of treatment of the samples with alkali ( $\mathrm{pH} 12.5$ ), which was 100 minutes. in place of 15 minutes, the destruction of cephalosporin $\mathrm{C}$ being complete in about one half of the time.

The broth came from a fermentation with a mutant derived from Cephalosporium acremonium, CMI 49137 mutant 8650 , the sample being taken at the point were the concentration of cephalosporin $\mathrm{C}$ reached the maximum. It was sterilized by Millipore filtration.

\section{Results}

Chromatograms of neutral, basic and acidic reaction mixtures, sampled at about $50 \%$ conversion of cephalosporin $\mathrm{C}$, and of a fermentation broth are shown in Fig. 1. The peaks designated 1, 2 and 3 are the parent compound, desacetyl cephalosporin $\mathrm{C}$ and the lactone of desacetyl cephalosporin $\mathrm{C}$. The peaks designated $\mathrm{U}$ have not been identified*). The shoulder on the left side of the lactone peak indicated poor resolution of the lactone and an other compound. The desacetyl peak in the broth did not desappear completely on treatment of the sample with alkali.

The course of the reaction at $\mathrm{pH} 10.1$ is shown graphically in Fig. 2. where the concentrations of the substrate, of desacetyl cephalosporin $\mathrm{C}$, and the sum of the two concentrations, expressed as mole percent of the initial concentration of the substrate, are plotted against the reaction time. The decomposition rate of cephalosporin $\mathrm{C}$ may be represented by the first order equation

$$
\ln \frac{C}{C_{0}}=-k_{1} t
$$

where $C_{0}$ is the initial concentration of the substrate and $C$ is concentration at time t. A first order plot of the data from the runs at $\mathrm{pH} 1.5$ and $\mathrm{pH} 10.1$ is shown in Fig. 3 (curves 1 and 2). The third curve represents the sum of the molar concentrations of the substrate $(C)$ and desacetyl cephalosporin $\mathrm{G}(D)$ for the run at $\mathrm{pH} 10.1$. When no appreciable concentrations of other cephalosporin derivatives are formed the rate constant $k_{2}$, defined by

$$
\ln \frac{C+D}{C_{0}}=-k_{2} t
$$

represents the rate of destruction of the nucleus. The values of $k_{1}$ and $k_{2}$ are summarized in Table 1 and plotted as a function of $\mathrm{pH}$ in Fig. 4.

In the early phase of this work, the reaction was followed by the differential spectrophotometric method ${ }^{8)}$, generally up to $60 \%$ conversion, as indicated by the spectrophotometric titer. The data in this range may also be represented by a first order equation and the rate constants $k_{3}$ are summarized in Table 2. Insofar as the extinction coefficients of cephalosporin $\mathrm{G}$ and the intermediates with an intact nucleus do not differ appreciably, and the differential optical density of the other products is negligible, $k_{3}$ is also a measure of the rate of destruction of the nucleus.

The decomposition rate of cephalosporin $\mathrm{C}$ in the broth sample, sterilized by

\footnotetext{
* Further experiments concerning the decomposition products formed in $0.05 \mathrm{M} \mathrm{HCl}$ were carried out after the completion of this work. In addition to the lactone of desacetyl cephalosporin C, 7-aminocephalosporanic acid and its decomposition products were detected. On a freshly packed column the relative retention times were : cephalosporin $\mathrm{C} 1.00$, desacetyl cephalosporin $\mathrm{C} 0.80$, 7-aminocephalosporanic acid 0.59 , desacetyl-7-aminocephalosporanic acid 0.52 , desacetyl cephalosporin C lactone 0.49 and desacetyl-7-aminocephalosporanic acid lactone 0.42 .
} 
Fig. 1. Chromatograms of buffer solutions at $50 \%$ decomposition of cephalosporin $\mathrm{C}$ and

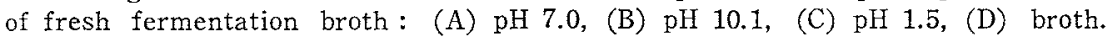
Peaks : cephalosporin $\mathrm{C}(1)$, desacetyl cephalosporin $\mathrm{C}(2)$, lactone (3), unknown $(U)$.
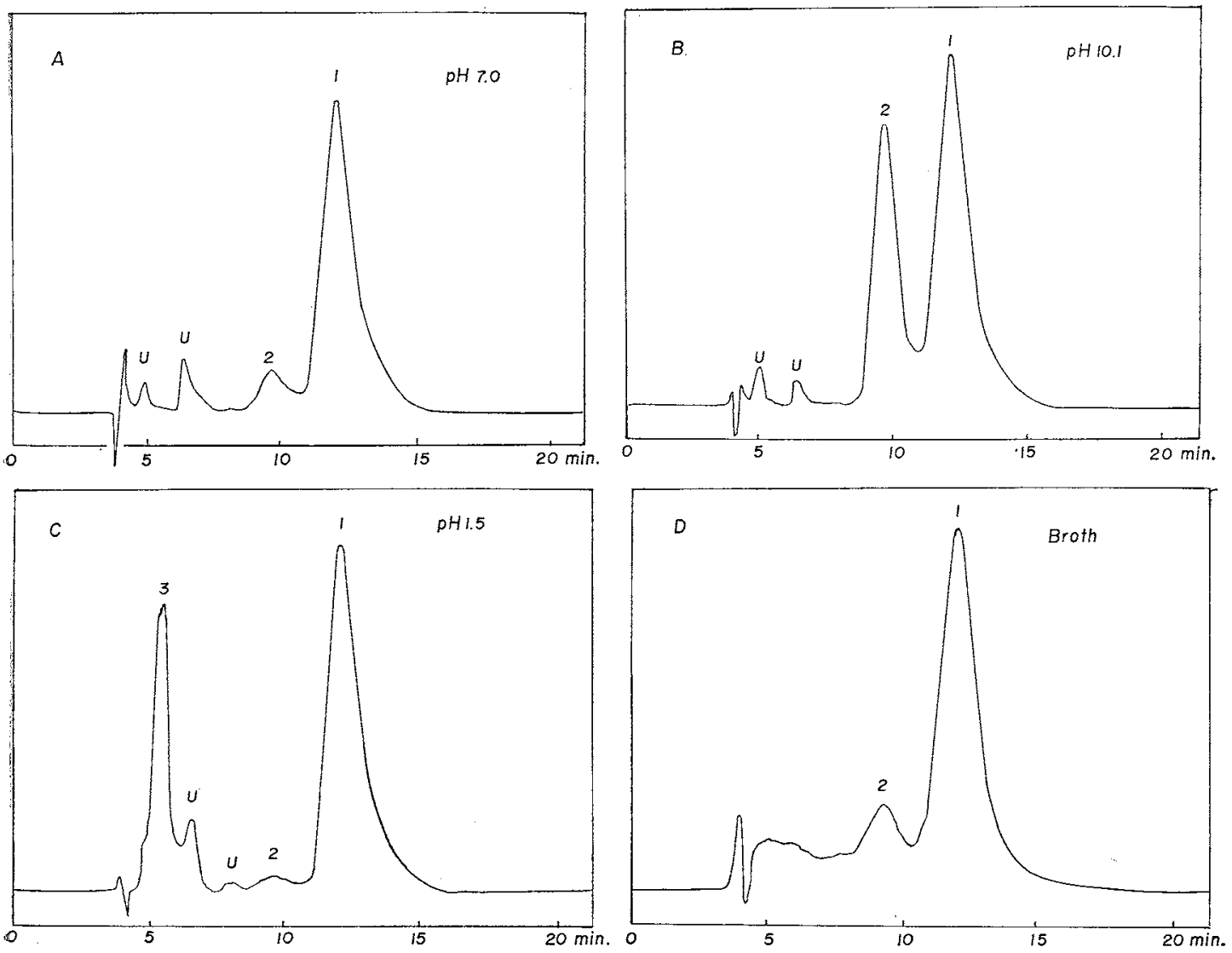

Millipore filtration, was $k_{1}=0.0054$ $\mathrm{h}^{-1}$ at $25^{\circ}$ and $\mathrm{pH} 6.5$ and agreed, within experimental error, with the value obtained by biological assay.

The decomposition rate of 7 aminocephalosporanic acid in 0.05 $\mathrm{M} \mathrm{HCl}, k_{\mathrm{l}}=0.022 \mathrm{~h}^{-1}$, had practically the same value as that of cephalosporin $\mathrm{C}$.

\section{Discussion}

Table 1. Reaction rate at $25^{\circ} \mathrm{C}$ as a function of $\mathrm{pH}^{2}$ )

\begin{tabular}{c|c|c|l}
\hline $\mathrm{pH}$ & $10^{3} k_{1}, \mathrm{~h}^{-1}$ & $10^{3} k_{2}, \mathrm{~h}^{-1}$ & \multicolumn{1}{|c}{ Buffer } \\
\hline 1.1 & 51 & - & $0.20 \mathrm{M} \mathrm{HCl}$ \\
1.5 & 20 & - & $0.050 \mathrm{M} \mathrm{HCl}$ \\
$2.9^{\mathrm{b})}$ & 6.6 & - & $0.20 \mathrm{M} \mathrm{CH}_{2} \mathrm{ClCO}_{2} \mathrm{H} / 0.10 \mathrm{M} \mathrm{NaOH}$ \\
$6.8^{\mathrm{b})}$ & 5.2 & - & $0.20 \mathrm{M} \mathrm{KH} \mathrm{PO}_{4} / 0.10 \mathrm{M} \mathrm{NaOH}$ \\
7.0 & 5.2 & 4.7 & $0.040 \mathrm{M} \mathrm{KH}_{2} \mathrm{PO}_{4} / 0.020 \mathrm{M} \mathrm{NaOH}$ \\
$8.1^{\mathrm{b}}$ & 6.2 & - & $0.049 \mathrm{M}$ Tris $/ 0.029 \mathrm{M} \mathrm{HCl}$ \\
8.3 & 7.4 & 5.2 & $0.021 \mathrm{M} \mathrm{Tris} / 0.010 \mathrm{M} \mathrm{HCl}$ \\
8.9 & 13.7 & 7.0 & $0.055 \mathrm{M} \mathrm{Tris} / 0.010 \mathrm{M} \mathrm{HCl}$ \\
10.1 & 76 & 19 & $0.040 \mathrm{M} \mathrm{NaHCO} / 0.020 \mathrm{M} \mathrm{NaOH}$ \\
12.5 & 13700 & 2700 & $0.030 \mathrm{M} \mathrm{NaOH}$ \\
\hline
\end{tabular}

a) Rates measured by liquid chromatography; initial concentration of cephalosporin $\mathrm{C} 0.5 \mathrm{~g} /$ /iter unless indicated otherwise; b) $4 \mathrm{~g} /$ liter cephalosporin $\mathrm{C}$.

The solid U-shaped curve in Fig. 4 representing the overall rate of cephalosporin $\mathrm{C}$ decomposition is characteristic of reactions which are susceptible to specific acid-base catalysis and which obey the rate law

$$
k_{1}=k_{a}\left(\mathrm{H}^{+}\right)+k_{w}+k_{b}\left(\mathrm{OH}^{-}\right)
$$

The curve was calculated with the following values of the rate constants: $k_{a}=0.27$ l.mole $\mathrm{e}^{-1} \cdot \mathrm{h}^{-1}, k_{w}=0.005 \mathrm{~h}^{-1}$ and $k_{b}=5 \times 10^{2} 1 . \mathrm{mole}^{-1} \cdot \mathrm{h}^{-1}$, the $\mathrm{pH}$ of the strongly acid solutions 
being based on the activities of hydrochloric acid.

The overall decomposition is a result of at least three independent primary reactions-ester, amide and $\beta$-lactam hydrolysis-with different $\mathrm{pH}$-rate profiles. The curves for the hydrolysis of ethyl acetate, and the slower hydrolysis of acetamide, are $\mathrm{V}$-shaped with a minimum near $\mathrm{pH}$ $3^{9)}$. (Rate data have been reported ${ }^{10,11}$, for the hydrolysis of $\gamma-, \delta$ - and $\varepsilon-$ lactams, but not of $\beta$-lactams). As a consequence of the different profiles, the ratio of the products changes with $\mathrm{pH}$.

The principal reaction in the flat region extending from $\mathrm{pH} 3$ to 7 is the attack of water on the nucleus. This is evident from the virtual absence of products with appreciable absorptivity at $254 \mathrm{~nm}$ (Fig. 1 A) and the agreement of the decomposition rates measured by the differential spectrophotometric method and by

Fig. 3. First order plots of rate data: (1) cephalosporin $\mathrm{C}$ at pH 1.5 (upper time scale), (2) same at $\mathrm{pH} 10.1$ (lower time scale), (3) cephalosporin C+desacety1 at $\mathrm{pH} 10.1$.

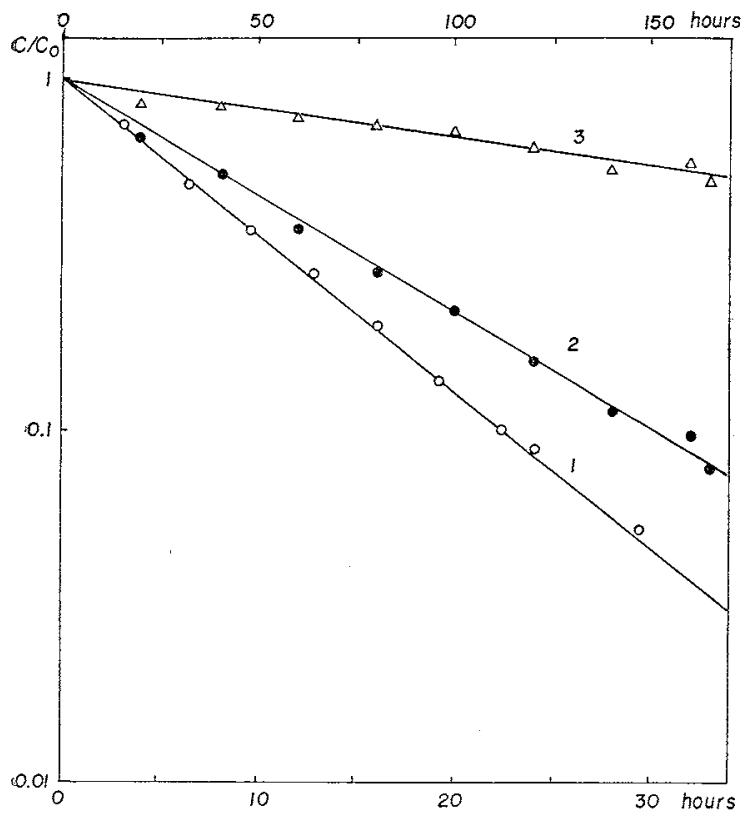

Fig. 2. Course of the reaction at $\mathrm{pH} 10.1$ : (1) cephalosporin $\mathrm{C}$, (2) desacetyl cephalosporin $C$, (3) sum of the two.

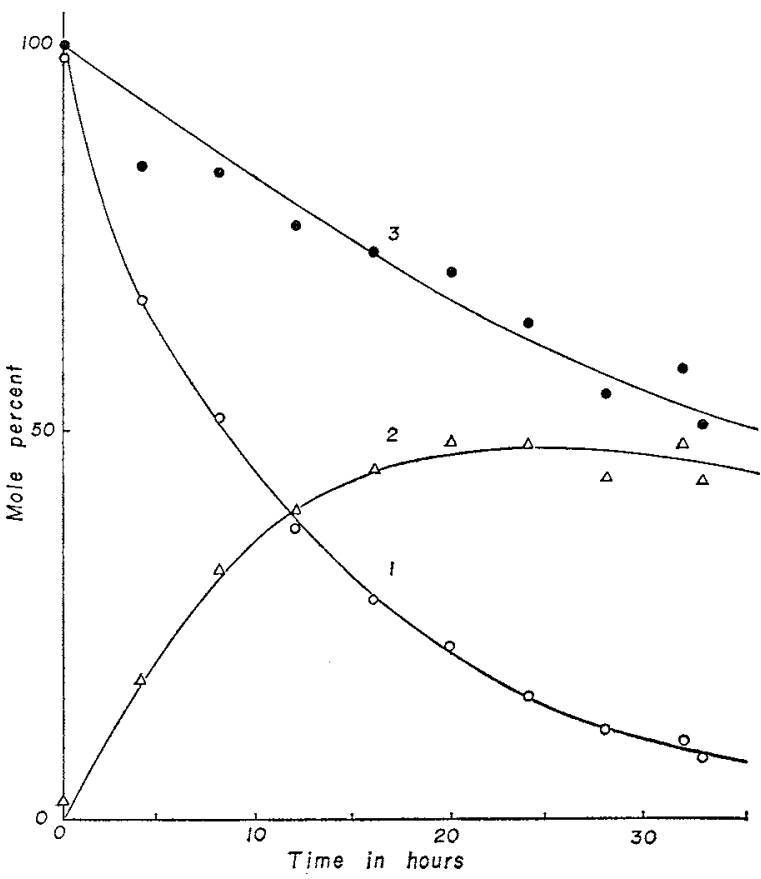

Fig. 4. The rate constants as a function of pH.

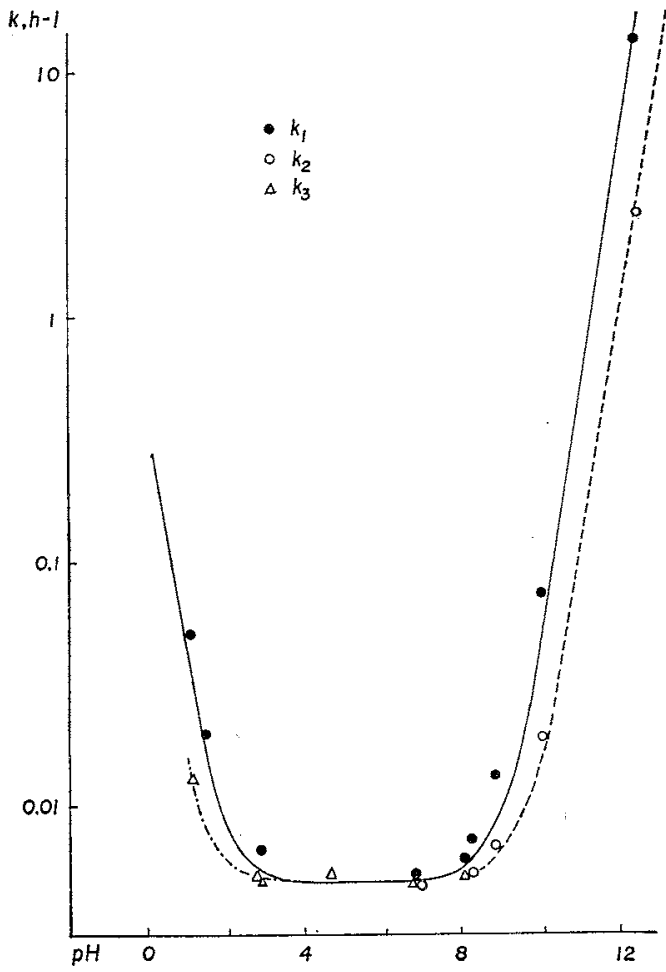


liquid chromatography.

In the acid region desacetylation proceeds at a significant rate relative to the destruction of the nucleus. The low concentrations of desacetyl cephalosporin $\mathrm{C}$ relative to the lactone indicate that the acid-catalyzed conversion of the desacetyl intermediate to the lactone is faster than its formation.

The principal reactions in the alkaline and intermediate $\mathrm{pH}$ region may be represented by the scheme

Cephalosporin $\mathrm{C}^{k_{4}} \longrightarrow$ Desacetyl cephalosporin $\mathrm{C}$

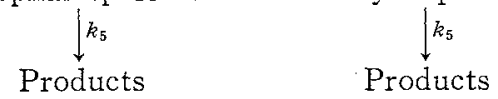

where $k_{5}$ is the rate of destruction of nucleus, taken to be the same for cephalosporin $\mathrm{C}$ and desacetyl cephalosporin $\mathrm{C}^{*}$.

Subject to this assumption the experimental rate constants $k_{1}$ and $k_{2}$ are simply related to $k_{4}$ and $k_{5}$, namely, $k_{1}=k_{4}+k_{5}$ and $k_{2}=k_{5}$. In the strongly alkaline region $k_{1} / k_{2} \cong 5$ and hence $k_{4} / k_{5} \cong 4$. Thus the base-catalized desacetylation is about four times as fast as the basecatalyzed destruction of the nucleus.

There is no evidence of enzymatic decomposition of cephalosporin $C$ in the broth tested**: The decomposition rate had practically the same value as the rate in a pure buffer of comparable $\mathrm{pH}$ and as the rate reported by HUBER and co-workers $^{3)}$ for sterile and inocculated broth. The quantity of cephalosporin C lost by non-enzymatic hydrolysis in a fermentation may be calculated from the production curve by the equation

$$
S_{t}=C_{t}+k_{1} \int_{0}^{t} C d t
$$

where $C_{t}$ is concentration of cepha-

Table 2. Reaction rates at $25^{\circ} \mathrm{C}$ as a function of $\mathrm{pH}^{\mathrm{a})}$

\begin{tabular}{c|c|c|l}
\hline $\begin{array}{c}\text { Cephalosporin } \\
\mathrm{C}(\mathrm{g} / \text { /iter })\end{array}$ & $\mathrm{pH}$ & $\begin{array}{c}10^{3} k_{3}, \\
\mathrm{~h}^{-1}\end{array}$ & \multicolumn{1}{|c}{ Buffer } \\
\hline 4.0 & 1.1 & 13 & $0.20 \mathrm{M} \mathrm{HCl}$ \\
1.0 & 2.8 & 5.2 & $0.20 \mathrm{M} \mathrm{CH} \mathrm{ClCO}_{2} \mathrm{H} / 0.10 \mathrm{M} \mathrm{NaOH}$ \\
4.0 & 2.9 & 4.9 & $0.20 \mathrm{M} \mathrm{CH}_{2} \mathrm{ClCO}_{2} \mathrm{H} / 0.10 \mathrm{M} \mathrm{NaOH}$ \\
4.0 & 2.9 & 5.0 & $0.20 \mathrm{M} \mathrm{CH}_{2} \mathrm{ClCO}_{2} \mathrm{H} / 0.10 \mathrm{M} \mathrm{NaOH}$ \\
1.0 & 4.7 & 5.2 & $0.20 \mathrm{M} \mathrm{CH}_{3} \mathrm{CO}_{2} \mathrm{H} / 0.10 \mathrm{M} \mathrm{NaOH}$ \\
4.0 & 6.8 & 4.8 & $0.20 \mathrm{M} \mathrm{KH}_{2} \mathrm{PO}_{4} / 0.10 \mathrm{M} \mathrm{NaOH}$ \\
4.0 & 8.1 & 5.2 & $0.049 \mathrm{M} \mathrm{Tris}_{4} / 0.029 \mathrm{M} \mathrm{HCl}$ \\
\hline
\end{tabular}

a) Rates measured by the differential spectrophotometric method.

losporin $\mathrm{C}$ in the broth at time $t, k_{1}$ the specific rate of hydrolysis at the given temperature and $\mathrm{pH}, S_{t}$ the concentration of cephalosporin $\mathrm{C}$ which would have been reached in time $t$ if no hydrolysis occurred, and where the integral represents the area under the production curve.

Curve 1 in Fig. 5 is quite similar to the production curve shown by HUBER and coworkers and may be taken as fairly typical of the fermentation. Curve 3 shows the production curve after correction for losses by hydrolysis, and curve 2 the total amount of product which had hydrolysed.

* In view of the structure of the two compounds, this assumption is reasonable. Furthermore large differences in reactivity would manifest themselves by a curvature of the first order plots of $C+D$ (see equation (2) and Fig. 3), which is not evident.

** There is, however, evidence of a cephalosporin $C$ destroying enzyme in broths fermented beyond the maximum yield of cephalosporin C (M. LIERSCH, communication). 
At 110 hours the loss amounts to $14 \%$ of the substance actually produced, the result of the calculation being independent of the concentration scale. This value corresponds to the level of desacetyl cephalosporin $\mathrm{C}$ in fermentation broth, reported by Huber and coworkers ${ }^{3)}$. However, at $\mathrm{pH} 7$ the main reaction is the destruction of the nucleus. Thus desacetyl cephalosporin $\mathrm{C}$ concentratons of the magnitude reported must have an other origin than the hydrolysis of the product.

\section{Acknowledgements}

We thank M. Sieber and A. Schneider for technical assistance and Dr.J. Nüesch for helpful discussions.

\section{References}

1) Abraham, E.P. \& G. G. F. Newton : The cephalosporins. Adv. Chemotherapy $20: 23 \sim 87,1965$

2) Morts, R. B. \& B. G. JACKson : Chemistry of cephalosporin antibiotics. Progr. in Chem. of Org. Nat. Products $28: 343 \sim 403,1970$

3) Huber, F. M.; R. H. Baltz \& P. G. CAltrider : Formation of desacetyl cephalosporin C in cephalosporin C fermentation. Appl. Microbiol. $16: 1011 \sim 1014,1968$

4) Jefrery, J. D'A.; E. P. Abraham \& G. G. F. Newron: Further degradation products of cephalosporin C. Biochem. J. $75: 216 \sim 223,1960$

5) Loder, B.; G. G. F. Newton \& E. P. Abraham: The cephalosporin C nucleus (7-aminocephalosporanic acid) and some of its derivatives. Biochem. J. $79: 408 \sim 416,1961$

6) Newton, G. G. F. \& E. P. Abraham: Cephalosporin C, a new antibiotic containing sulphur and D- $\alpha$-amino-adipic acid. Nature $175: 548,1955$

7) JgfFery, J. D'A.; E. P. Abraham \& G. G. F. Newton: Desacetylcephalosporin C. Biochem. J. $81: 591 \sim 596,1961$

8) Clatidga, C. A.; R. W. Vaughan, P. Kressel \& A. Gourevimsch : Spectrophotometric assay for cephalosporin $C$ in fermentation broths. Antimicr. Agents \& Chemoth. $-1969: 131 \sim 134,1970$

9) BENDER, M. L.: Mechanism of catalysis of nucleophilic reactions of carboxylic acid derivatives. Chem. Rev. $60: 53 \sim 113,1960$

10) Farber, S. J. \& J. A. Brieux : Mechanism of acid hydrolysis of $\epsilon$-caprolactam. Chem. \& Ind. (London) : 599 600, 1966

11) Vinnik, M. I. \& Y. V. Moiseyev : Mechanism of the hydrolysis of lactams in aqueous solutions of potassium hydroxide. Tetrahedron $19: 1441 \sim 1454,1963$ 